УДК 347.91, 341.981

DOI https://doi.org/10.17308/vsu.proc.law.2021.1/3276

\title{
ОДНОСТОРОННИЕ ГИБРИДНЫЕ СОГЛАШЕНИЯ О ЮРИСДИКЦИИ: КОНЕЦ ДИСКУССИИ ДЛЯ РОССИИ?
}

\author{
В. В. Бакуменко \\ Национальныцй исследовательский университет \\ "Высшая школа эконолики" \\ Поступила в редакцию 1 сентября 2020 г.
}

\begin{abstract}
Аннотация: расслатривается эволющия подходов российских судов, сфбормулированньх в отношении вопросов действительности и исполнимости односторонних гибридных оговорок. Приводится критический анализ теоретической и политико-правовой обоснованности соответствующих подходов с точки зрения как действующего правового регулирования, так и совреленных тендениий, выработанных в различных юрисдикииях. Основываясь на последних раздяснениях Верховного Суда РФ, автор приходит $\kappa$ выводу, что на современном этапе односторонние гибридные оговорки будут признаваться недействительньли российскили судали. При этол отлечается, что подобный подход требует переосльсления в контексте мировых тендениий толкования основных приниипов права.

Ключевые слова: международный гражданский процесс, международный колмерческий арбитраж, юрисдикиионные соглашения, гибридные оговор$\kappa и$, асимлетричные оговорки.
\end{abstract}

Abstract: the article examines the evolution of the approaches of Russian courts formulated in relation to the issues of validity and enforceability of unilateral hybrid clauses. At the same time, the research provides for critical analysis of the theoretical, political and legal substantiation of the respective approaches from the point of view of both the current legal regulations and trends developed in various jurisdictions on the issue considered. Based on the latest clarifications of the Supreme Court of the Russian Federation, the author concludes that at the present stage unilateral hybrid clauses will be recognized as invalid by Russian courts. Simultaneously, it is noted that such approach requires reconsideration in the context of global trends in the interpretation of the main principles of law. Key words: international civil procedure, international commercial arbitration, jurisdiction clauses, hybrid clauses, unilateral option clauses, asymmetric clauses.

Рост трансграничных споров между представителями различных юрисдикций обусловливает актуальность целого ряда вопросов, связанных как с действительностью и исполнимостью заключаемых соглашений о международной подсудности, так и с последующим признанием и исполнением вынесенных на их основании судебных и арбитражных решений. В связи с этим субъекты предпринимательской и фринансовой деятельности, руководствуясь строго прагматичными подходами и стре-

(C) Бакуменко B. B., 2021 
мясь снизить потенциальные риски, устанавливают не только дополнительные обязательственные гарантии, но и всё чаще выбирают более сложные юрисдикционные оговорки, сочетающие в себе элементы различных правовых институтов, а также предусматривающие нестандартное распределение прав сторон.

Одними из наиболее распространенных в этом контексте стали соглашения о способе разрешения споров, которые предусматривают для сторон возможность обращения не только в государственный, но и в арбитражный суд. Такого рода «гибридные» соглашения содержат как пророгационный, так и арбитражный элемент, а выбор форума остается скрытым до тех пор, пока предполагаемый спор не возникнет из соглашения ${ }^{1}$. В российской и иностранной юридической литературе можно встретить различные обозначения таких соглашений: гибридные (hybrid clauses), опционные (option clauses), комбинированные оговорки (combined clauses), оговорки с правом выбора (Klauseln mit Wahlrecht) ${ }^{2}$.

Вместе с тем в зависимости от объема прав сторон в отношении выбора передачи дела в арбитраж или государственный суд в доктрине различаются: 1) двусторонние гибридные соглашения, в рамках которых правом выбора наделены обе стороны и 2) односторонние гибридные соглашения, предусматривающие право выбора только у одной из сторон ${ }^{3}$. Именно последний вид гибридных соглашений привлек наибольшее внимание в практической и теоретической плоскостях, поскольку, как и с большинством нестандартных правовых конструкций, распределение прав в таких соглашениях является более сложным, чем кажется на первый взгляд.

Несмотря на отсутствие универсального подхода в терминологии ${ }^{4}$, односторонние гибридные соглашения по своему характеру и содержанию могут быть определены как процессуальные соглашения сторон в отношении юрисдикции, предусматривающие, что в случае возникновения спора одна из сторон договора (как правило, кредитор) имеет исключительное право выбора фрорума 5 . Классическим примером односторонней

${ }^{1}$ См., например: Draguiev D. Unilateral Jurisdiction Clauses: The Case for Invalidity, Severability or Enforceability // Journal of International Arbitration. 2014. Vol. 31, № 1. P. 23.

${ }^{2}$ Все упомянутые термины используются в представленной статье как синонимичные.

${ }^{3}$ См., например: Барбе Ж., Рошер П. Опционные оговорки о способах разрешения споров : анализ с точки зрения французского и английского права // Вестник междунар. коммерческого арбитража. 2011. № 1(3). С. 110-126 ; Зенькович Д. И. Асимметричные арбитражные соглашения в России и за рубежом // Междунар. право и междунар. организации. 2013. № 4. С. 534-549 ; Ходыкин Р. М. Гибридные оговорки о рассмотрении спора // Вестник Высшего Арбитражного Суда РФ. 2012. № 11. C. 60-70.

${ }^{4}$ Cм.: Smit H. The Unilateral Arbitration Clause: A Comparative Analysis // American Review of International Arbitration. 2009. Vol. 20, № 3. P. 394.

${ }^{5}$ Cм.: Niddam L. Unilateral Arbitration Clauses in Commercial Arbitration // Arbitration and Dispute Resolution Law Journal. 1997. P. 147. 


\section{Вестник ВГУ. Серия: Право}

гибридной оговорки является стандартная арбитражная оговорка, которая в качестве дополнительного структурного элемента предусматривает право только одной из сторон инициировать спор в компетентном государственном суде (т. е. односторонний элемент оговорки с пророгационной составляющей) ${ }^{6}$.

Включение таких положений в соглашение может быть очень выгодным для стороны, в пользу которой такое дополнительное (исключительное) право предусмотрено, поскольку в случае возникновения спора такая сторона может выбрать наиболее благоприятный в сложившихся обстоятельствах форум для его разрешения. Это отчасти предопределило наибольшую популярность использования односторонних гибридных оговорок в кредитных договорах с крупными финансовыми институтами и банками, которые, выступая в качестве кредиторов, наиболее заинтересованы в минимизации потенциальных рисков взыскания задолженности и сокрытия активов ${ }^{7}$.

Тем не менее большинство вопросов, касающихся односторонних гибридных соглашений, остаются плохо изученными, хотя ответы на них определяют применимость и действительность таких соглашений в принципе. Кроме того, из-за объективных различий в материальном и процессуальном регулировании подходы в различных юрисдикциях к такому типу соглашений также очень сильно различаются, что ставит под сомнение их практическую эффективность ввиду неоднозначных выводов, складывающихся в отношении их действительности и исполнимости. Государственные суды в целом ряде юрисдикций выработали совершенно разные подходы к таким соглашениям, которые продолжают эволюционировать и иногда очень противоречиво ${ }^{8}$.

Эволюция судебной практики российских государственных судов в

- этом отношении не является исключением и представляет собой один 은 из наиболее ярких примеров консервативного подхода на международном уровне. При этом стоит отметить, что еще до конца 2018 г. позиция российских судов в отношении гибридных соглашений не была четко обозначена, однако уже тогда было очевидно, что односторонние гибридные соглашения могут вызвать серьезную правовую неопределенность в рамках правоотношений сторон. В отсутствие четкого подхода и двусмысленных выводов было трудно предвидеть, какие именно проблемы может породить институт гибридных оговорок в каждом конкретном случае.

Прежде чем перейти к негативному подходу, который сложился в российской правоприменительной практике, следует отметить, что как и в

${ }^{6}$ Cм.: Nesbitt S., Quinlan H. The Status and Operation of Unilateral or Optional Arbitration Clauses // Arbitration International. 2006. Vol. 1. P. 146.

${ }^{7}$ Cм.: Stacey J., Taylor A. Unilateral Jurisdiction Clauses in the UK // International Financial Law Review. 2013. URL: http://www.iflr.com/Article/3258087/Unilateral-jurisdiction-clauses-in-the-UK.html (дата обращения: 27.08.2020).

${ }^{8}$ Cм., например: Ahmed M. The Legal Regulation and Enforcement of Asymmetric Jurisdiction Agreements in the European Union // European Business Law Review. 2017. Vol. 28, № 3. P. 403. 
ряде других юрисдикций, исторически российские суды рассматривали односторонние гибридные оговорки в качестве действительных и исполнимых. Как показывает анализ российской судебной практики, до 2012 г. российские арбитражные суды руководствовались подходом, преимущественно сорормированным Федеральным арбитражным судом Московского округа по ряду споров, инициированных финансовыми учреждениями в рамках кредитных договоров, содержащих соответствующие асимметричные положения ${ }^{9}$. Соглашения включали арбитражную оговорку, а также предусматривали право кредитора инициировать судебное разбирательство в судах Англии или любой другой компетентной юрисдикции. В каждом конкретном случае кредиторы инициировали действия в Арбитражном суде г. Москвы. Хотя суды первой и апелляционной инстанций поддержали доводы ответчика и прекратили разбирательство, суд кассационной инстанции рассмотрел иск по существу и подтвердил действительность асимметричного арбитражного соглашения. Кроме того, было подчеркнуто, что сторона, несущая финансовые риски (кредитор), на законных основаниях наделена правом выбора механизмов определения порядка разрешения споров, содержащихся в соглашении.

Аналогичный вывод был сделан в деле по иску иностранной компании Рэд Барн Кэпитал ЛЛК к ЗАО «Факторинговая компания «Еврокоммерц» ${ }^{10}$. В данном деле спор касался договора, который предусматривал арбитражное разбирательство в рамках Лондонского международного арбитражного суда (LCIA), но с некоторыми исключениями. В частности, соглашение также предусматривало, что если фринансовая сторона представит свои возражения до назначения арбитров, то соответствующий спор может быть передан в юрисдикцию государственного суда. В связи с задержкой исполнения обязательств компания Рэд Барн Кэпитал ЛЛК обратилась в Арбитражный суд г. Москвы, который оставил исковое заявление без рассмотрения, указав на отсутствие компетенции суда в связи с арбитражным соглашением, заключенным между сторонами. В ходе дальнейшего рассмотрения спора суды поддержали позицию первой инстанции, указав на действительность предусмотренной договором юрисдикционной оговорки. Несмотря на то что соглашение устанавливало более широкий круг прав кредитора в части выбора механизма определения порядка разрешения споров, суды нашли такое распределение прав обоснованным и законным, поскольку оно было направлено на защиту интересов стороны, которая находится в более рисковом положении.

${ }^{9}$ См., например: Постановления Федерального арбитражного суда Московского округа : от 23 декабря 2009 г. № КГ-А40/13340-09 ; от 12 января 2010 г. № КГА40/14014-09 и от 18 января 2010 г. № КГ-40/14211-09. Аналогичная позиция ранее также была представлена в постановлении Федерального арбитражного суда Северо-Западного округа от 23 сентября 2005 г. по делу № A21-2499/03-С1.

${ }^{10}$ Определение Арбитражного суда г. Москвы от 28 августа 2012 г. по делу № A40-59745/09-63-478 ; постановление Девятого арбитражного апелляционного суда от 22 сентября 2009 г. № 09АП-16829/2009-ГК по делу № А40-59745/09-63478 ; постановление Арбитражного суда Московского округа от 28 декабря 2009 г. № КГ-А40/13190-09 по делу № А40-59745/09-63-478. 
В 2012 г. позитивный подход к институту гибридных оговорок резко изменил свою траекторию развития после вывода Президиума Высшего Арбитражного Суда РФ, представленного в рамках известного дела по иску ООО «Русская телефонная компания» к ЗАО «Сони Эриксон Мобайл Коммюникейшнз Рус» в связи с поставкой продукции ненадлежащего качества ${ }^{11}$. Юрисдикционное соглашение между сторонами предусматривало, что все споры из договора должны разрешаться Международным арбитражным судом при МТП (ICC International Court of Arbitration), при этом продавец был наделен исключительным правом обращаться в государственные суды компетентной юрисдикции. В нарушение указанного пункта покупатель обратился с исковым заявлением в Арбитражный суд г. Москвы, который оставил заявление без рассмотрения в силу положений ст. 148 АПК РФ и ссылкой на арбитражную оговорку в договоре, заключив, что он не обладает юрисдикцией для рассмотрения спора. Такой подход был поддержан судами апелляционной и кассационной инстанции, которые дополнительно указали, что заключенное соглашение соответствует принципу автономии воли сторон.

Тем не менее в рамках надзорного производства, инициированного истцом, Президиум Высшего Арбитражного Суда РФ отменил судебные акты нижестоящих судов и направил дело на новое рассмотрение. В частности, Президиум Высшего Арбитражного Суда РФ, руководствуясь рядом разъяснений Конституционного Суда $Р \Phi^{12}$ и Европейского суда по правам человека ${ }^{13}$, установил, что одной из гарантий справедливого разрешения споров является равное право сторон на представление своих позиций в судах или иных судебных инстанциях (включая арбитраж), а принципы состязательности и процессуального равенства сторон требуют, чтобы стороны имели равные процессуальные возможности для осуществления справедливого судебного разбирательства.

В связи с этим был сделан вывод о том, что односторонняя гибридная оговорка, предоставляющая право передавать спор в государственный суд одной из сторон соглашения и лишающая такого права другую сторону, является недействительной. Иными словами, вторая сторона соглашения, обладающая равными процессуальными правами со своим контрагентом, также должна иметь право обратиться в компетентный государственный суд с целью реализации своего законного права на судебную защиту и доступ к правосудию. Таким образом, вышестоящая ин-

${ }^{11}$ Постановление Президиума ВАС РФ от 19 июня 2012 г. № 1831/12 по делу № A40-49223/11-112-401.

12 Постановления Конституционного Суда РФ: от 20 июля 2011 г. № 20-П ; от 27 фревраля 2009 г. № 4-П ; от 8 декабря 2003 г. № 18-П ; от 14 февраля 2000 г. № 2-П ; от 14 апреля 1999 г. № 6-П ; от 10 декабря 1998 г. № 27-П ; от 2 июля 1998 г. № 20-П.

${ }^{13}$ В частности, постановления ЕСПЧ: от 26 мая 2009 г. № 3932/02 «Бацанина против Российской Федерации»; от 15 февраля 2005 г. № 68416/01 «Стил и Моррис против Соединенного Королевства»; от 15 октября 2009 г. № 23243/03 «Сокур против Российской Федерации». 
станция, основываясь на «общих принципах защиты гражданских прав», принципах состязательного судопроизводства и процессуального равенства, пришла к заключению о том, что соглашение о подсудности не может носить диспаритетный характер, предоставляя только одной стороне право обращаться в компетентный государственный суд и одновременно ограничивая аналогичное право другой.

Сформулированные Высшим Арбитражным Судом РФ выводы были лишены четкой определенности и, как следствие, привели к относительно большому объему критики со стороны юридического сообщества, в том числе за отсутствие ясности в дальнейшем толковании положений российского законодательства. Во-первых, высшая судебная инстанщия не указала, признала ли она недействительным спорное соглашение полностью или только его часть, которая носила асимметричный характер ${ }^{14}$; во-вторых, был ли механизм определения фрорума, предусмотренный соглашением, переквалифицирован в симметричный (двусторонний), наделяющий обе стороны правом выбора между разбирательством в арбитраже и в рамках государственного судопроизводства ${ }^{15}$. Исходя из формулировок Высшего Арбитражного Суда РФ, формально оговорка не была признана недействительной, хотя ее конструкция претерпела изменения, и согласованный сторонами механизм определения форума был лишен своей первоначальной цели защиты прав кредитора.

Тем не менее, даже если исходить из того, что Президиум Высшего Арбитражного Суда РФ переквалифицировал одностороннее гибридное соглашение в двустороннее, имеются основания сомневаться в обоснованности и правомерности такого подхода. В силу положений п. 2 ст. 450 Гражданского кодекса РФ суд имеет право изменять положения договора только в том случае, если соответствующее требование будет заявлено одной из сторон в порядке и конкретных случаях, установленных законом. Таких заявлений в рассмотренном деле сделано не было. При этом представляется, что такая переквалификация в принципе является очень узкой и может быть применена только в отношении односторонних гибридных оговорок в части пророгационного элемента, предоставляющего только одной стороне право обращаться в компетентные государственные суды. В противном случае предложенное Высшим Арбитражным Судом РФ решение теряет всякую рациональность и применимость, поскольку трудно представить, что российский государственный суд будет заинтересован в распространении арбитражной части соглашения на другую сторону.

Неопределенная позиция Президиума Высшего Арбитражного Суда РФ не только внесла двусмысленность в отношении толкования асимметричных соглашений в теории, но и, как следствие, стала результатом

${ }^{14}$ См.: Ходыкин Р. М. Гибридные оговорки о рассмотрении спора // Вестник Высшего арбитражного суда Российской Федерации. 2012. № 11. С. 64.

${ }^{15}$ См.: Егоров A. B. Асимметричные оговорки о разрешении споров судебная практика заменяет на симметричные // Вестник междунар. коммерческого арбитража. 2012. № 2. C. 188. 


\section{Вестник ВГУ. Серия: Право}

появления противоречивых судебных актов в последующей правоприменительной практике. Так, в деле 2014 г. кассационный суд отклонил заявление ОАО «Новокузнецкий холодильный комбинат» о приведении в исполнение арбитражного решения, вынесенного в соответствии с односторонней гибридной оговоркой ${ }^{16}$. Ссылаясь на подход 2012 г., суд пришел к аналогичному выводу, что оговорка недействительна, поскольку нарушает равенство прав сторон и общий принцип процессуального равенства сторон. Суд не смог дополнительно объяснить конкретные правовые основания, по которым он признал решение, как не имеющее юридической силы. Однако можно предположить, что ссылка на нарушение публичного порядка как основание для отказа в исполнении, вероятно, была учтена судом: в качестве дополнительного основания суд также установил, что вторая сторона не была должным образом уведомлена об арбитражном разбирательстве.

Еще большую двусмысленность в регулировании гибридных односторонних оговорок в России внесла позиция Коллегии по экономическим спорам Верховного Суда РФ, сорормулированная в деле по заявлению ООО «Пирамида», о признании и приведении в исполнение арбитражного решения против ООО «БОТ», вынесенного на основе асимметричного арбитражного соглашения ${ }^{17}$. Спорное соглашение предусматривало, что «истец» имеет право выбирать между арбитражем и судебным разбирательством по своему усмотрению. Ввиду нарушения покупателем обязательств по основному договору ООО «Пирамида» инициировало арбитражное разбирательство. Арбитражное решение было вынесено в пользу истца, однако не было исполнено добровольно, в связи с чем истец обратился в российский государственный суд за принудительным исполнением. Суды первой и кассационной инстанции отказали в принудительном исполнении, руководствуясь позицией Высшего Арбитражного Суда РФ, и признали соглашение недействительным.

Между тем Верховный Суд РФ указал на ошибочное толкование нижестоящими судами выводов Высшего Арбитражного Суда РФ и отменил судебные акты. Как было отмечено, в отличие от фрабулы дела 2012 г. в рассмотренном споре сторона, которая имела исключительное право выбора форума, не была определена a priori, а подлежала определению

64 только в момент получения соответствующего процессуального статуса. Следовательно, формулировка «по выбору истиа» не нарушает баланс прав сторон, поскольку при заключении подобного типа соглашений равенство процессуальных прав сторон гражданского судопроизводства не затрагивается. Иными словами, подобный механизм определения фрорума наделяет каждую сторону правом подать иск в компетентный государственный суд или арбитражное учреждение в соответствии с условиями соглашения.

${ }^{16}$ Постановление ФАС Центрального округа от 3 июля 2014 г. по делу № A62949/2014.

17 Определение Судебной коллегии по экономическим спорам Верховного Суда РФ от 27 мая 2015 г. № 310-ЭС14-5919 по делу № А62-1635/2014. 
Несмотря на то что выводы Верховного Суда РФ стали логическим шагом в эволюции регулирования односторонних гибридных оговорок в России, сложно сделать вывод, что они не устранили проблему полностью. С одной стороны, Верховный Суд РФ признал действительность и исполнимость гибридных оговорок, однако фрактически такое признание было сделано в отношении двусторонней (симметричной) модели, поскольку в рассмотренном случае исключительное право было поставлено в зависимость от процессуального статуса истца, который может получить любая из сторон договора. Вместе с тем спорные выводы Высшего Арбитражного Суда РФ, касающиеся одностороннего закрепления процессуальных прав, так и не были должным образом проанализированы. $\mathrm{C}$ другой стороны, как отмечают некоторые авторы, ввиду новой позиции Верховного Суда РФ открылись дополнительные риски инициирования параллельных производств недобросовестными контрагентами ${ }^{18}$.

Данный вывод представляется достаточно актуальным и обоснованным, учитывая, что подобного рода соглашения создают дополнительные стимулы для недобросовестной стороны как можно раньше инициировать процесс в наиболее благоприятном ей форуме для реализации исключительного права. Иными словами, существует риск «торпедирования исков». Конечно, в юрисдикциях, благоприятствующих арбитражу, существуют механизмы против такого оппортунистического поведения сторон, однако аналогичные инструменты в действующем российском законодательстве не предусмотрены ${ }^{19}$. Следовательно, вопрос регулирования гибридных оговорок не был разрешен окончательно и оставался в поле правовой неопределенности.

Анализ последующей судебной практики позволяет выявить альтернативный подход, который был выработан судами и предусматривал признание одностороннего гибридного соглашения недействительным в полном объеме как в арбитражной, так и в пророгационной части. Данный подход был впервые сформирован Верховным Судом РФ в 2016 г. по иску

${ }^{18}$ Cм.: Samoylov M. The Evolution of Unilateral Arbitration Clauses in Russia // Kluwer Arbitration Blog. October 1, 2015. URL: http://arbitrationblog.kluwerarbitration.com/2015/10/01/the-evolution-of-unilateral-arbitration-clauses-in-russia/?doing wp_cron=1598455825.7182331085205078125000 (дата обращения: 26.08.2020).

${ }^{19}$ Вместе с тем стоит обратить внимание, что 19 июня 2020 г. вступил в силу Федеральный закон от 27 мая 2020 г. № 171-ФЗ «О внесении изменений в Арбитражный процессуальный кодекс Российской Федерации в целях защиты прав физических и юридических лиц в связи с мерами ограничительного характера, введенными иностранным государством, государственным объединением и (или) союзом и (или) государственным (межгосударственным) учреждением иностранного государства или государственного объединения и (или) союза», который внес изменения в АПК РФ, установив среди прочего право российских арбитражных судов устанавливать судебный запрет в отношении участника спора. Новый процессуальный инструмент отчасти представляет собой аналог английского института "anti-suit injunction», однако его узкая применимость не дает оснований для его рассмотрения в качестве эффрективного инструмента в рамках рассматриваемой проблематики. 
иностранной компании Имеджинг Маркетс Страктчед Продактс Б.В. к $\mathrm{OOO}$ «Жилиндустрия» и других поручителей по гарантии ${ }^{20}$, подчиненной английскому праву. Кредитор обратился в Арбитражный суд г. Москвы по месту жительства одного из ответчиков. Иск был удовлетворен в полном объеме, хотя ответчики пытались утверждать, что он должен быть оставлен без рассмотрения по существу в силу юрисдикционной оговорки, предусмотренной договором. Тем не менее суды признали одностороннее гибридное соглашение недействительным (как в арбитражной, так и в пророгационной части) и установили нарушение баланса процессуальных прав сторон, который имеет имманентный характер. В связи с этим судами были применены общие нормы о подсудности (ст. 34-37 АПК РФ), предусмотренные российским процессуальным законодательством, которые применяются для определения юрисдикции и компетенции российских судов, а не для определения действительности арбитражного или пророгационного соглашения, что составляло ключевой вопрос спора.

Несмотря на то что вопрос применимого права в указанном деле не входил в предмет спора, представляется важным обратить внимание на еще один момент. Учитывая, что гибридные соглашения структурно формируются из арбитражной и пророгационной частей, то и применимое право к таким соглашениям подлежит дифференцированному установлению, т. е. к каждой части соглашения отдельно. Соответственно, вопросы о допустимости передачи спора в арбитраж и в иностранный государственный суд будут разрешаться на основании двух различных блоков норм. На обоснованность подобного подхода неоднократно обращали внимание зарубежные исследователи ${ }^{21}$, однако до настоящего времени проблема не получила надлежащего развития в рамках российской судебной практики.

26 декабря 2018 г. Президиум Верховного Суда РФ предпринял попытку положить конец давней дискуссии и сформулировал достаточно четкую позицию в отношении гибридных соглашений о подсудности в рамках обзора судебной практики, касающейся содействия и контроля в отношении третейских судов и международных коммерческих арбитражей ${ }^{22}$. В указанном обзоре Верховный Суд РФ определил, что асимметричные оговорки нарушают принципы состязательности и равенства

${ }^{20}$ Постановление Арбитражного суда Московского округа от 14 марта 2016 г. № Ф05-726/2016 по делу № А40-125181/2013 ; определение Верховного Суда РФ от 6 июля 2016 г. № 305-ЭС16-7033 по делу № А40-125181/2013.

${ }^{21}$ См., например: Hartley T., Dogauchi M. Explanatory Report on the Preliminary Draft Convention on Choice of Court Agreements. Prel. Doc. № 25. 2004. Para. 60. URL: https://www.hcch.net/en/publications-and-studies/details4/?pid=3510\&dtid=35 (дата обращения: 25.08.2020) ; Briggs A. Agreements on jurisdiction and choice of law. Oxford: Oxford University Press, 2008. P. 72, 75, 81.

22 Обзор практики рассмотрения судами дел, связанных с выполнением функций содействия и контроля в отношении третейских судов и международных коммерческих арбитражей : утв. Президиумом Верховного Суда РФ 26 декабря 2018 г. 
сторон и, следовательно, являются недействительными в той мере, в которой такие оговорки предусматривают неравенство сторон в праве выбора фрорума. Вследствие этого считается, что каждая сторона договора имеет равные права на выбор форума, согласованного в пункте об урегулировании споров.

Тем не менее обозначенный в обзоре подход сложно назвать обоснованным и отвечающим современным правовым тенденциям. Основным аргументом в отношении нарушения баланса прав сторон Верховный Суд РФ называет нарушение принципа процессуального равенства, который предполагает справедливое судебное разбирательство. Однако, как следует из практики Европейского суда по правам человека, процессуальное равенство «подразулевает, что каждой стороне должна быть предоставлена разулная возложность представить свое дело... при условиях, которые не ставят его в существенно невыгодное положение по сравнению с его оппонентол» ${ }^{23}$. Хотя значение принщипа равноправия сторон вполне очевидно ${ }^{24}$, тем не менее стоит согласиться с рядом экспертов, что этот принцип может быть применен только к уже начатой процедуре разрешения спора. Между тем односторонние гибридные оговорки предоставляют возможность выбора места разрешения споров и не влияют на саму процедуру инициированного арбитража или судебного разбирательства. Данный вывод подтверждается также практикой иностранных судов. Например, в одном из дел, касающихся действительности односторонней гибридной оговорки, английский суд указал, что принцип процессуального равенства подразумевает «доступ к правосудию в рамках форума, выбранного сторонами, а не к выбору суда» ${ }^{25}$.

Кроме того, стоит более подробно остановиться на вопросе, почему принцип процессуального равенства сторон до сих пор не является абсолютным. Во-первых, требование равного доступа к правосудию не может быть реалистично применено таким образом, чтобы каждая сторона фактически имела равные права и позицию в судебном разбирательстве. Представляется, что альтруистическое допущение абсолютного равноправия неизбежно выходит за рамки сложных реалий международных судебных и арбитражных разбирательств. Асимметричное распределение прав между участниками международного арбитража иллюстрируется среди прочего ограничениями в участии новой стороны на более поздних стадиях процесса, которые могут выражаться, например, в запрете выдвигать возражения по процедуре фрормирования состава арбитров ${ }^{26}$.

${ }^{23}$ Dombo Beheer B. V. v. The Netherlands, App № 14448/88, IHRL 2585 (ECHR 1993).

${ }^{24}$ Cm.: Article 6 of the European Convention on Human Rights and Fundamental Freedoms, as amended by Protocols Nos. 11 and 14, 4 November 1950, ETS 5. URL: http://www.refworld.org/docid/3ae6b3b04.html (дата обращения: 25.08.2020).

${ }_{25}$ Mauritius Commercial Bank Limited v. Hestia Holdings Limited, Sujana Universal Industries Limited, 2 Lloyd's Rep. 755 (Ch., 2005).

${ }^{26}$ См., например: Пункт $7 \S 13$ Правил арбитража международных коммерческих споров Международного коммерческого арбитражного суда при Торго- 
Во-вторых, трудно понять, почему свободно заключенный договор, в отсутствие серьезных нарушений прав и явных недобросовестных намерений сторон, может рассматриваться как нарушение прав участников процесса. В альтернативном, но все же связанном контексте прецедентное право демонстрирует, что сторона, признавшая исключительную юрисдикцию английских судов, не может предъявлять иски о нарушении прав в соответствии со ст. 6 Европейской конвенции по правам человека, если английский суд выносит судебный запрет, чтобы предотвратить подачу иска в другом месте ${ }^{27}$. Даже если указанная норма будет применима в этом контексте, представляется весьма спорным, что он будет относиться к вопросам выбора стороной юрисдикции.

При этом принцип равенства сторон, предусмотренный Европейской конвенцией по правам человека, касается процессуального положения сторон перед конкретным судебным органом, но не равенства в выборе органа (института) проведения разбирательства. Таким образом, некоторые принудительные ограничения права стороны на подачу иска, например судебный запрет в англо-саксонской правовой традиции (anti-suit injunction), который лишает заявителя возможности подать иск в любом месте, могут, как правило, нарушать требование доступа к правосудию. Этот принцип также будет нарушен, если результатом ограничения выбора суда может быть их принудительное обращение в суд, в котором они не получат беспристрастного и незаинтересованного процесса, однако в таких случаях неравенство в выборе органа рассмотрения спора не является источником нарушения права стороны на судебную защиту. Источником нарушения, как представляется, является скорее объем гражданских прав и обязанностей стороны в процессе, который лишает ее права на справедливое и беспристрастное разбирательство.

Возвращаясь к последней позиции Верховного Суда РФ, важно отметить следующее. Несмотря на то что обзор формально не имеет обязательной силы, он дает ценное руководство к подходу, который российские суды, вероятно, будут использовать в отношении односторонних гибридных соглашений в дальнейшем. Представляется, что подход российских судов в краткосрочной перспективе будет оставаться достаточно консервативным, рассматривающим односторонние гибридные оговорки как нарушающие принцип процессуального равенства. В связи с этим существует явный риск того, что российские суды могут отказать в исполнении арбитражного решения, вынесенного в соответствии с односторонней гибридной оговоркой. Вместе с тем одностороннее право выбора форума также оставляет открытой возможность для ответчика в арбитраже, инициированном в соответствии с такой оговоркой, начать разбирательство в российских судах в качестве истца (при условии, что судами будет установлено наличие личной или территориальной подсудности). Помимо

во-промышленной палате РФ ; п. 5 § 9 Правил арбитража корпоративных споров Международного коммерческого арбитражного суда при Торгово-промышленной палате РФ.

${ }^{27}$ OT Africa Line Ltd v. Hijazy (The Kribi), 1 Lloyd's Rep 76 (QBD, 2001). 
дополнительных расходов, такое разбирательство может поставить под угрозу возможность принудительного исполнения арбитражного решения в России в дальнейшем.

Тем не менее стороны вправе заключить более «широкое» по фрормулировке соглашение, предусматривающее исключительное право выбора форума не для конкретного лица, а в отношении процессуального статуса стороны соглашения в случае возникновения спора. Хотя подобные соглашения трудно рассматривать как асимметричные с точки зрения теории и механизма их действия, тем не менее они предоставляют участникам гражданского оборота некоторую дискрецию в использовании нестандартного распределения процессуальных прав в случае возникновения потенциальных споров.

Таким образом, при заключении нестандартных соглашений о подсудности с российскими контрагентами сторонам следует тщательно оценивать, насколько риски, связанные с исполнимостью и действительностью асимметричных положений, смогут нивелировать преимущества, которые будет иметь сторона в случае включения таких положений. Между тем вопрос обоснованности сформировавшегося подхода российских судов продолжает оставаться актуальным и требует дальнейшего переосмысления с учетом современных тенденций развития международного процессуального права на глобальном уровне.

Национальный исследовательский университет "Высшая школа экономики"

Бакуменко В. В., аспирант, ассистент департалента правового регулирования бизнеса фбакультета права

E-mail: bakumenko.vasily@gmail.com
National Research University "Higher School of Economics"

Bakumenko V. V., Post-graduate Student, Assistant of the Department of Legal Regulation of Business Faculty of Law

E-mail: bakumenko.vasily@gmail.com 